\title{
The conceptual model of information confrontation of virtual communities in social networking services
}

\author{
Kateryna Molodetska ${ }^{1}$, Yuriy Timonin ${ }^{2}$, Ihor Melnychuk ${ }^{3}$ \\ ${ }^{1,2}$ Department of Computer Technologies and Systems Modeling, Zhytomyr National Agroecological University, Ukraine \\ ${ }^{3}$ Social Sciences Department, Zhytomyr National Agroecological University, Ukraine
}

\begin{tabular}{l} 
Article Info \\
\hline Article history: \\
Received Sep 15, 2019 \\
Revised Oct 7, 2019 \\
Accepted Oct 15, 2019 \\
\hline
\end{tabular}

Keywords:

Antagonistic conflict Information warfare Model

Social networking services

Virtual communities

\begin{abstract}
Social networking services are one of the most popular mass media and are used as an effective tool for information confrontation due to their functional characteristics. Existing models of information confrontation take into account the redistribution between conflict parties of only one kind of resource, although in the social networking services there is a need to consider additional factors that determine the effectiveness of virtual communities' opposition. A conceptual model of information confrontation of virtual communities in social networking services has been developed, and it includes three-layer dynamics of the number of actors, growth of information resources of virtual communities and dynamics of spending resources for the confrontation conduct. The model also takes into account the peculiarities of the antagonistic conflict of virtual communities' actors through the choice of a differential equation that corresponds to the type of its dynamics. The offered conceptual model formalizes the behavior of virtual communities' actors in the conditions of antagonistic conflict. At the same time, it allows to investigate the peculiarities of using different strategies to carry out the information fight of virtual communities in social networking services, to choose optimal strategies, to predict the development of conflicts in the information space and to develop effective measures to counter threats to the state's information security.
\end{abstract}

Copyright $\odot 2020$ Institute of Advanced Engineering and Science. All rights reserved.

\section{Corresponding Author:}

Kateryna Molodetska,

Department of Computer Technologies and Systems Modeling,

Zhytomyr National Agroecological University,

7, Staryy Blvd., 10008, Zhytomyr, Ukraine.

Email: kmolodetska@gmail.com

\section{INTRODUCTION}

Due to the deepening of the processes of society informatization, a significant transformation of the processes of social communication has taken place. Currently, social networking services (SNS) are not only a mass media, but are also used by users (actors) to unite like-minded people in virtual communities, to express civic position, to coordinate real-life actions and, as a consequence, to influence political and social processes in the state. The global and Ukrainian experience of using SNS by citizens for selforganization in alarming situations and during resonant events has shown that they are an effective tool for influencing public opinion, mobilizing citizens and strengthening protest sentiment in society [1-5]. Such phenomena have become possible due to the high degree of actor's confidence in SNS information compared with the traditional media. Also, as a result of a radical change in communication processes in the information space, SNS has turned into an effective means of conducting a new form of opposition a hybrid war. The hybrid war combines political, economic, information, and other tools to gain advantage by one state to the other. A leading role in conducting the hybrid war is played by information confrontation as a contention between social systems or countries in the information sphere to influence different spheres of 
public relations and to establish control over sources of strategic resources, whereby one party receives the benefits it needs for its further development. Under current conditions, the advantage in the state's information space is gained due to the high speed of content distribution in SNS, which has a destructive information impact on actors, as well as the decentralized nature of the links between them. As a result, SNS are an effective and efficient online platform for conducting offensive actions in the national information space of the state [6-14]. Therefore, at the present stage of the development of information technologies and the formation of the information society, SNS has become a source of threats to the information security of the state. Considering the multifunctionality of SNS and in the context of globalization of information space and free circulation of content in the world, there is an objective contradiction between the urgent need for practice in ensuring the sustainable development of the services' information space and the problem of science to develop effective methodological bases for modeling the conflict interaction in the information space for keeping the state's information security in SNS.

Analysis of recent research and publications has shown that, at the present stage of technology development, the hybrid war is being run without the use of military capabilities and weapons in the classical sense $[7,10,15,16]$. Due to the use of SNS, information confrontation becomes latent, has no clear beginning and end, and, as a result, the cross-border interaction between actors in SNS, the borders of states become vague. In turn, the content distributed during information operations contains a destructive information and information-psychological impact. This leads to complicated procedures of formalizing information confrontation processes and their modeling, taking into account unique situations and certain important factors.

It is known from publications [7, 10, 16-26] that mathematical models which take into account the redistribution of different types of resources necessary for its realization are used to study the processes of information confrontation. Among the known models of war, the most common model is the Lanchester model [17-19], which envisages the quantitative dynamics of the battle of two groups as a random Markov process with discrete states and continuous time. For such a process it is possible to obtain the equations of average dynamics and to determine at any given time the average numbers of confrontation parties. In practice, the Lanchester model is used to predict the average number of defeated and undefeated war units in each group at any given time. The disadvantage of this model is a significant decrease in the accuracy of the modeling results while reducing the number of actors of opposing virtual communities in SNS. The Lotki-Volterra model (or the "predator-prey" model) has also gained wide popularity for the study of information confrontation in SNS [12, 20-22]. This model describes a population consisting of two interacting species. The first of them is "predators", in the absence of the second - "preys" die out, while the second in the absence of predators is multiplied extensively in accordance with the law of Malthus. In the general case, this model describes the number of actors of virtual communities in SNS who are carriers or followers of a certain narrative or formalize the actors' interaction. However, the use of the Lotki-Volterra model in the information confrontation of actors' virtual communities in SNS is limited only to its certain aspects and, for example, cannot formalize the number of actors in opposing virtual communities.

Differential pursuit games are also used for mathematical description and to investigate the interaction between conflicting parties in SNS [23-25]. Whereas, two groups of actors in SNS are considered - catching up and running away. The purpose of the virtual catching-up community of actors is to move a vector to a given set in the shortest period of time, and the purpose of the running-away community is to increase the duration of such a transition. The disadvantages of this approach are the assumption that the behavior of the enemy is deterministic and each group should be aware of the possible strategies of each other. Also, differential pursuit games do not take into account the risks connected with social communication processes in SNS, and the optimal searched strategies use only one index or criterion. A common drawback of these approaches to formalizing and investigating the information confrontation of virtual communities in SNS is performing of its description at the resource level - in particular, the number of actors in the virtual community. The experience of hybrid war between Ukraine and the Russian Federation shows that the effectiveness of information confrontation in SNS is determined not only by the number of supporters of some narratives, but also by the emergent properties and synergistic effects in the social engineering system that affect the real social processes in the country. Therefore, the models of information confrontation of virtual communities in SNS must take into account more factors than the existing models. Also, the predator-prey model [20-22] does not fulfill the main condition of the conflict - the number of actors in SNS remains unchanged, and the gain of one virtual community must be equal to the loss of another. Considering the complexity of the processes of actors' interaction in SNS in the conditions of a constant hidden float of threats to the information security of the state, a promising area of research is the selection of information confrontation of equations' components in the mathematical model that take into account: changing the conflict characteristics of the actors' interaction in virtual communities; growing in the level of resources due to the increase in the number of virtual communities' actors in SNS; the resource 
spending in order to conduct information operations in SNS in the context of confrontation. Therefore, the study of the information confrontation processes of virtual communities' actors in SNS requires the development of mathematical models that will ensure the realization of the conflict condition above. This, in turn, further mainstreams the chosen area of research. The purpose of the article is to develop a unified systemic position of the conceptual model of the information confrontation process of virtual communities' actors in SNS, the application of which will improve the effectiveness of modeling the conflict interaction in the information space.

\section{FEATURES OF ACTORS' ANTAGONISTIC INTERACTION OF OPPOSING VIRTUAL COMMUNITIES IN SNS}

The information confrontation of virtual communities in SNS is reduced to disseminating content with opposing narratives of open or hidden features to gain significant benefits in the information space, which will create backgrounds for further development and involvement of new actors. The display of actors' information confrontation in SNS is, in particular, the antagonistic conflict of virtual communities, which appears as a result of extreme tension and aggravation of contradictions and leads to active actions, complications and struggles, accompanied by complex conflicts of interests, beliefs, ambitions.

Definition 1. The antagonistic conflict of virtual communities in SNS will be called the interaction between communities in the services' information space, characterized by intransigence and hostility between them and displayed in the conflict of ideological, political, social, economic, religious and other interests.

From the game theory aspect [26, 27] it is known that the features of the mathematical model of the situation such as a game are the following: 1) the number of parties in the conflict is two; 2) the behavior of actors in SNS is characterized by uncertainty associated with the presence of several options for each participant; 3) differences (variances) in the interests of participants; 4) the interdependence of the actors' behavior, since the result obtained by each of them depends on the behavior of all participants of opposing virtual communities; 5) the existence of the behavior rules known to all actors in virtual communities. Thus, in an antagonistic conflict of actors' virtual communities in SNS, the behavior of opposing parties is characterized by the following features: the actors' function in different phase spaces - physical, economic, informational, cultural and others; increasing the number of actors in one virtual community is achieved by reducing the size of the other virtual community, and the gain of one opposing party is equal to the loss of another. The total number of actors in virtual communities is constant; improving the functioning of one virtual community is carried out by increasing the number of actors who are followers and ideas men, by means of another virtual community; strategies for the behavior of actors in antagonistic conflict are: capture (attack), protect (defense), and counter-attack operations.

\section{THE CONCEPTUAL MODEL ESSENCE OF INFORMATION CONFRONTATION IN VIRTUAL COMMUNITIES IN SNS}

The mathematical modeling of conflict interaction $[15,28]$ is effectively used for the study of wars, so it can be applied to formalize the information component of the hybrid war in SNS. As a result of the undertaken studies the conceptual model of processes of antagonistic interaction in virtual communities is proposed, the construction of which leads to the following steps.

Step 1. Formalization of the three-layer model of information confrontation in SNS. The model of antagonistic interaction of virtual community actors is a structure that has three components.

Definition 2. A layer of the information confrontation model of virtual communities in SNS will be called the differential equation system, which describes a particular aspect of such interaction in the SNS information space.

Model layer 1 describes the antagonistic conflict of participants using the characteristics of the subject area - the phase space in which the participants interact. The conflict is that the winning of one participant is equal to the loss of the other participant, or in other words, the increase of the phase space of information conflict of one participant is related to its decrease of another. The analyzed layer describes the dynamics of the number of two virtual communities in SNS and that are in antagonistic conflict in the SNS information space. In this case, the winning of one virtual community is equal to the loss of another. The essence of the winning or loss of each opposing virtual community in SNS is to increase or, accordingly, reduce the number of its actors.

Model layer 2 describes the benefits of information conflict such as the growth of some resource associated with the need for conflict. The winning model can be considered as an assessment of the confrontation efficiency to determine the function of conflict effectiveness. In SNS, this layer formalizes 
the growth of resources and virtual communities as a result of information confrontation in SNS, and is determined by the total share of the information space of services, which will disseminate content of directed matter by actors who have joined this community. Then the effectiveness of conflict interaction in the SNS information space is supported by the actor's ideology of some virtual community, that is why it produces and disseminates content with its defined narrative not only in SNS among interconnected actors, but also in the society.

Model layer 3 is the model of failures (loss) from information confrontation in the form of growing of some expenditure-related resource and that accompanies a conflict. The loss model can also be considered as a characteristic for assessing conflict cooperation in order to determine the function of conducting the confrontation's effectiveness. In the context of the conflict interaction of virtual communities in SNS, this model layer determines the dynamics of resource expenditures for information operations in the information space of services. It is known that conducting information confrontation in SNS envisages the involvement of significant resources - human, money, technical, etc. Therefore, consideration of this aspect will allow to materialize a comprehensive approach to the study of the virtual communities' confrontation.

Step 2. Choosing equations of the conflict dynamics interaction of virtual communities in SNS. Choosing the type of differential equation of the conflict dynamics is important for studying the peculiarities of its behavior in the SNS information space. Differential equations must meet the requirement of adequacy and include several control parameters. Table 1 summarizes the approaches to choosing the equation form of information confrontation in virtual communities.

Table 1. Types of conflict dynamic models of virtual communities in SNS

\begin{tabular}{|c|c|c|}
\hline $\begin{array}{l}\text { The dynamic } \\
\text { type }\end{array}$ & $\begin{array}{l}\text { An example of the } \\
\text { mathematical model }\end{array}$ & Characteristics \\
\hline uniform & direct equation & $\begin{array}{l}\text { the conflict of opposing virtual communities develops gradually, with the winning and losing } \\
\text { rates that increase by a set amount at the same time intervals; }\end{array}$ \\
\hline accelerated & exponential equation & $\begin{array}{l}\text { with increasing duration of conflict between opposing virtual communities, the rate of } \\
\text { winning and losing growth increases exponentially; }\end{array}$ \\
\hline S-shaped & logistic equation & $\begin{array}{l}\text { reflects the rapid growth, respectively, of the winning and losing of virtual communities at } \\
\text { the beginning of information confrontation, followed by the accelerated slowdown of this } \\
\text { process in the final stages, and a further asymptotic approach to some level }\end{array}$ \\
\hline
\end{tabular}

\section{AN EXAMPLE APPLICATION OF THE CONCEPTUAL MODEL}

We choose the S-shaped dynamic type of information confrontation of virtual communities' actors in the form of logistic function, which combines accelerated growth in the initial and accelerated slowdown in the final phase of antagonistic conflict, and also includes the control parameters [29-30]. This approach allows us to formalize the conflicting interaction of virtual communities in the form of a system of differential equations by means of parametric rather than functional dependence as in the known models [29, 30].

Therefore, we choose the general equation of limited growth as the equations for the conflict dynamics. An expression for the general equation of limited growth in the form of a second-order nonlinear differential equation [30]

$$
a_{2} z^{\prime \prime}(t) z(t)+\left(1+a_{1} z(t)\right) z^{\prime}(t)+\left(a_{0} z(t)-\varphi\right) z^{\theta}(t)=0
$$

where $z(t)$ - is the investigated value; $a_{2}, a_{1}, a_{0}$ - are the parameters that represent the vectors of hidden control over actors in the SNS virtual community. The choice of differential (3) is due to its ability to reflect the processes of growth of the studied quantity - the number of virtual communities, resources and expenditures, up to a given threshold value. Thus, $a_{2}=0$ and $\theta=1$ from differential (3) we obtain the logistic equation of the generalized form [29].

$$
\left(1+a_{1} z(t)\right) z^{\prime}(t)+\left(a_{0} z(t)-\varphi\right) z(t)=0
$$

The solution to this logistic equation is the generalized logistic growth function of the investigated quantity, which describes the antagonistic conflict of virtual community actors in SNS. Therefore, the threelayer mathematical model of information confrontation of actors' virtual communities in SNS based on logistic equation takes the following form. 
1) The first layer of the model - is the dynamics of the number of two virtual communities in SNS

$$
\left\{\begin{array}{l}
(1+a x(t)) x^{\prime}(t)+\psi(x(t) / X-1) x(t)=0 \\
(1+b y(t)) y^{\prime}(t)+\varphi(y(t) / Y-1) y(t)=0
\end{array}\right.
$$

where $a, b-$ are the parameters that determine the levels of actors' critical thinking of the corresponding virtual communities in SNS; $\psi, \varphi-$ are the parameters that characterize the rate of publications' growth of directed content in the information spaces of opposing virtual communities; $X, Y-$ are the limit numbers of virtual communities in SNS.

Limitation 1. The variables' constraint equation of the information confrontation's first layer model of actors' virtual communities in SNS is given by the limitation on the total number of all actors $x(t)+y(t)=N(t)=$ const,$X+Y=N=$ const.

Remark 1. The dependence of the numbers of virtual communities of actors in antagonistic conflict interaction from the outer implicit control is given by the following expressions $x(t)=f(t, u), y(t)=f(t, v)$.

Limitation 2. The information confrontation between virtual communities in SNS is modeled in the absence of implicit control of actors.

2) The second layer of the model is the growth of resources $r(t)$ and $s(t)$ of virtual communities as a result of information confrontation in SNS

$$
\left\{\begin{array}{l}
(1+c r(t)) r^{\prime}(t)+\alpha(r(t) / R-1) r(t)=0, \\
(1+d s(t)) s^{\prime}(t)+\beta(s(t) / S-1) s(t)=0 ;
\end{array}\right.
$$

where $c, d$ - are the parameters that determine the actors' resistance of one virtual community to the spreading of the narrative of another opposing virtual community; $\alpha, \beta-$ are the parameters that characterize the activity of spreading by virtual communities' actors that have become members of an opponent group defined by the narrative in the SNS information space; $R, S-$ are the limit values of virtual community information resources in SNS.

Remark 2. The limits of resources $r(t)$ and $s(t)$ of virtual communities depend on the thresholds of the actors' number. In simple cases, we confine ourselves to a linear dependence of the form $R=\lambda X$, $S=\mu Y$.

Limitation 3. The requirement of a constant sum of the virtual community resource thresholds for the second layer of the model does not disseminate. This is due to the non-deterministic behavior of the actors, which is defined by the individual characteristics of the frequency creation and publication of the content of each service user.

3) The third layer of the model is the resource dynamics' expenditures for information confrontation in SNS

$$
\left\{\begin{array}{l}
(1+g p(t)) p^{\prime}(t)+\zeta(p(t) / P-1) p(t)=0, \\
(1+h q(t)) q^{\prime}(t)+\xi(q(t) / Q-1) q(t)=0
\end{array}\right.
$$

where $g, h$ - are the parameters that define the costs of virtual community resources to protect actors from outer influences and maintain their numbers; $\zeta, \xi$-is the intensity of resources' expenditures for carrying out information operations in services in order to attract new actors; $P, Q$ - is the maximum amount of resources allocated for conducting information confrontation to virtual communities.

\section{RESULTS AND ANALYSIS}

To formalize different strategies of information confrontation of actors in SNS, let us decompose the motion (5) into two components that reflect the movement of individual virtual communities of the conflict participants: the dynamic equation of the number of the virtual community 1 (VC1), where the number of actors of this community is calculated, and the other - is defined by the leftover principle 


$$
\left\{\begin{array}{l}
x_{k+1}=\left(1+\psi\left(1-x_{k} / X\right) /\left(1+a x_{k}\right)\right) x_{k} \\
Y=N-X
\end{array}\right.
$$

The dynamic equation of the number of the virtual community 2 (VC2), where the number of actors of this community is calculated, and the other - is defined by the leftover principle, calculate in a similar way.

Attack and defense strategies. We consider the situation where VC1 conducts an information campaign in order to increase its size by attracting some of VC2's actors. The increase in the number of actors $\mathrm{VC} 1$ at the expense of $\mathrm{VC} 2$ participants is reflected in the model by increasing the threshold value. The results of calculations made in the table processor based on expression (8) are presented in Figure 1.

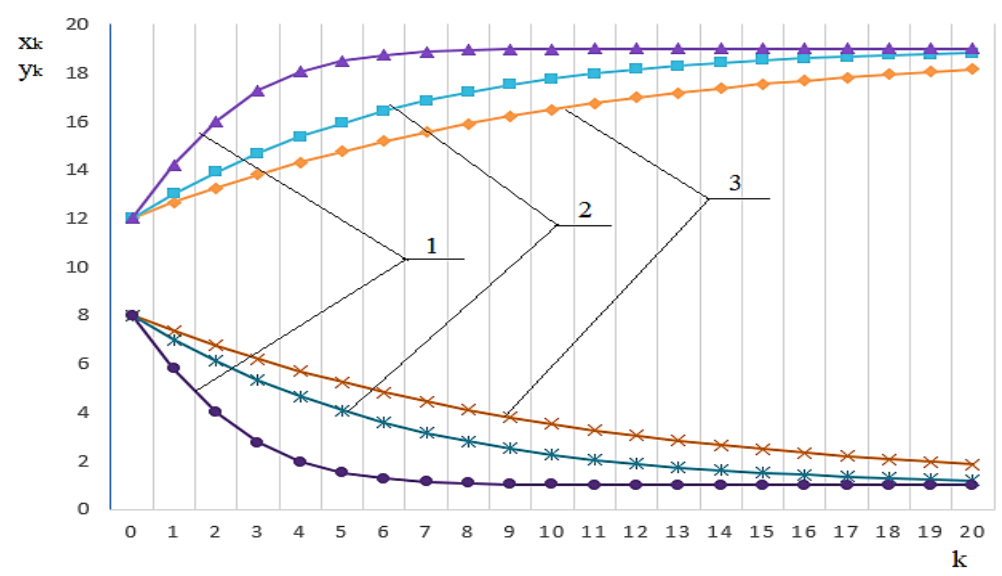

Figure 1. The change in the number of virtual communities at the criticality levels of perception the content by actors: $1-; 2-; 3-a=b=0,2$

For the calculations, the normalized values of the initial number of actors, which are $x_{0}=12, y_{0}=8$ and $n_{0}=20$ are used. At the same time, it is accepted that the rate of increase in the number of publications in the information spaces of opposing virtual communities is $\psi=\varphi=0,5$ from the total published content of the communities. Figure 1 shows that as a result of the attack, the number of $\mathrm{VC} 1$ increases and goes to the limits $X=19$, and the number of participants in $\mathrm{VC} 2$ decreases and goes to the limits $Y=1$ consequently. The members of the virtual community may oppose the spreading of the content of directed matter in the SNS information space in the context of information confrontation. Such processes are related to the control of the parameters of the first layer model (5) $a$ and $b$ which define the levels of actors' critical thinking of the corresponding virtual communities. In turn, the growth of their values slows the speed of reaching asymptotically the limits of the virtual community. Therefore, by varying the parameters $a$ and $b$ of the differential equations' system (5), they model operations to protect the information space of the virtual community during the antagonistic conflict between groups of actors.

To model the growth of $\mathrm{VC} 1$ resources on the basis of the second layer model of information confrontation in virtual communities, we write a system of differential (6) in the form of expression (8). The normalized values of indexes have been used. We suppose that the threshold values for the numbers and resources of VC1 and VC2 are connected by the linear dependence as the following $R=X, S=Y$. In this case, the initial value of the $\mathrm{VC} 1$ volume resource that has carried out the information attack on VC2 equals $r(0)=1$, and the threshold values are $R=12$ (initial) and $R=19$ (final). The initial resource value for VC2 is $s(0)=1$, and the corresponding limits are $S=8$ (initial) and $S=1$ (final).

As Figure 2 shows, the result of an information attack is that the resources of $\mathrm{VC} 1$ grow and go to the limit of $R=19$ units. In this case, the rate of $\mathrm{VC} 1$ resources' growth at the cost of $\mathrm{VC} 2$ resources depends on its opposition, the quantity of which is set by the parameter values opposing to the narrative spreading of the confrontation community in its SNS information space. The calculations assume that the parameters of the distribution activity of a certain narrative by actors, which have been redistributed to virtual communities after the information attack, are like $\alpha=\beta=0,6$. 


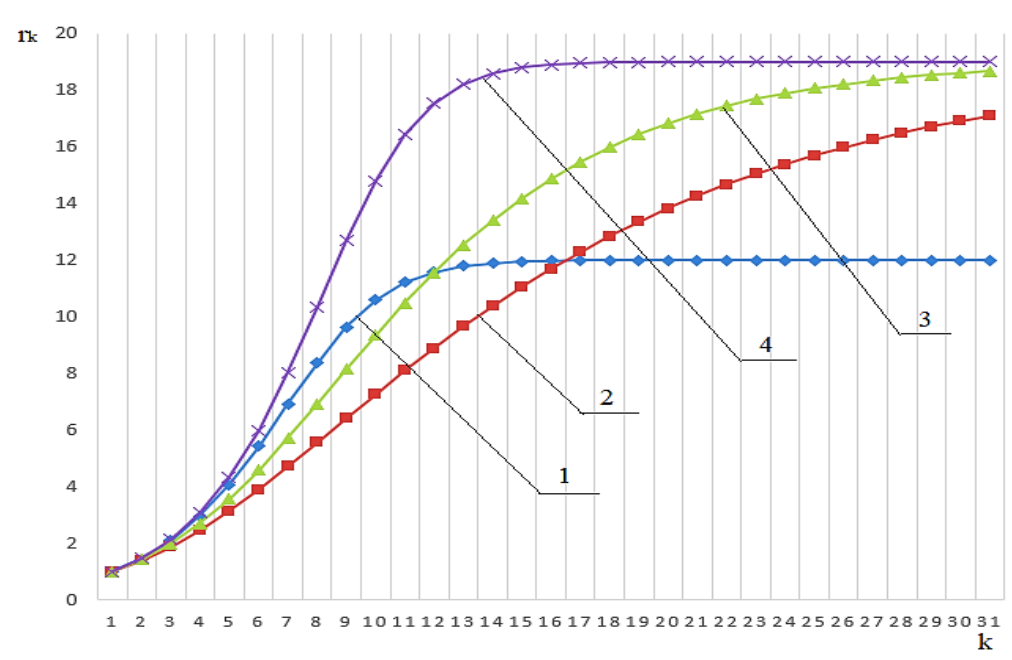

Figure 2. The change of VC1 resources after the information attack:

$$
1-R=12, c=0 ; 2-R=19, c=0,2 ; 3-R=19, c=0,1 ; 4-R=19, c=0
$$

Figure 3 proves the resources' dynamics of VC2, which has carried out information attack in SNS. As a result of capturing VC1 resources, VC2 resources are reduced and asymptotically directed to the predetermined limits. The decreasing rate of VC2 resources is defined by the value of its participants' resistance, which is gaining the following value.

Counter-attacking strategy. The essence of carrying out a counter-attack strategy during an antagonistic conflict in the SNS information space is that VC2, after reducing its size as a result of an information attack by $\mathrm{VC} 1$, starts a counterattack, which increases its number to a given value and provides the growing of its resources. The normalized quantities of the studied values are used for the calculations. We assume that at the moment of counter-attack in the information space, the initial value of VC2 resources equals $s(0)=1$, the purpose of counter-attack is to increase gradually the available resources to the final limits $S=9$.

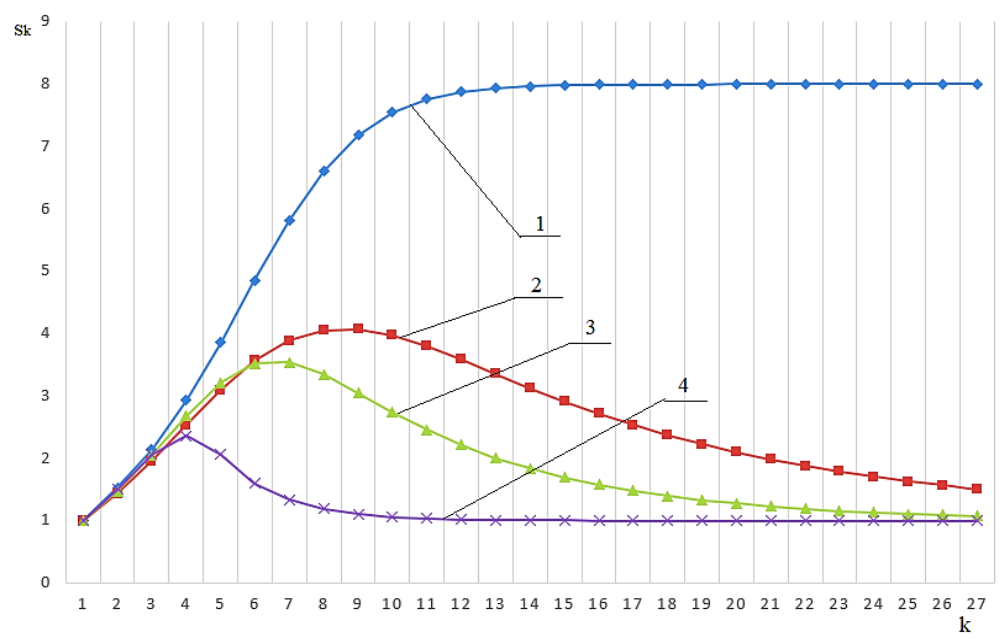

Figure 3. The dynamics of VC2 resources after an information attack on it: $1-S=8, d=0 ; 2-S=1, d=0,2 ; 3-S=1, d=0,1 ; 4-S=1, d=0$

As it can be seen from Figure 4, as a result of the counterattack, VC2 not only returns the amount of its own resources before the beginning of information confrontation $S=8$, but also increases it up to $S=9$. The analysis of results of modeling the information confrontation of two virtual communities in SNS using the developed conceptual model allows us to draw the following conclusions. Firstly, the three-layer model 
(5) - (7) allows to consider not only the change in the number of virtual community actors who are in antagonistic conflict in SNS, but also the redistribution between them in the process of confronting resources of the information space the service and the dynamics of spending money, human and technical resources for direct information confrontation. Secondly, the parameters' variation of the differential equation system (5)-(7) allows to take into account the behavior peculiarities of the virtual community actors while conducting information confrontation and changing the information space of the services themselves. In particular, the ability of community members to take a critical view of the opposing party's narrative, their publishing activity in SNS, the resources' expenditures to protect the information space of their own community, and so on. Thirdly, the worked out conceptual model allows us to explore the peculiarities of different strategies use of information struggle in virtual communities and their combinations. At the same time, it can be used to select the optimal strategy, extrapolate the conflict dynamics of the actors' communities in the SNS information space and develop effective measures for comprehensive threats counteraction to the information security of the state.

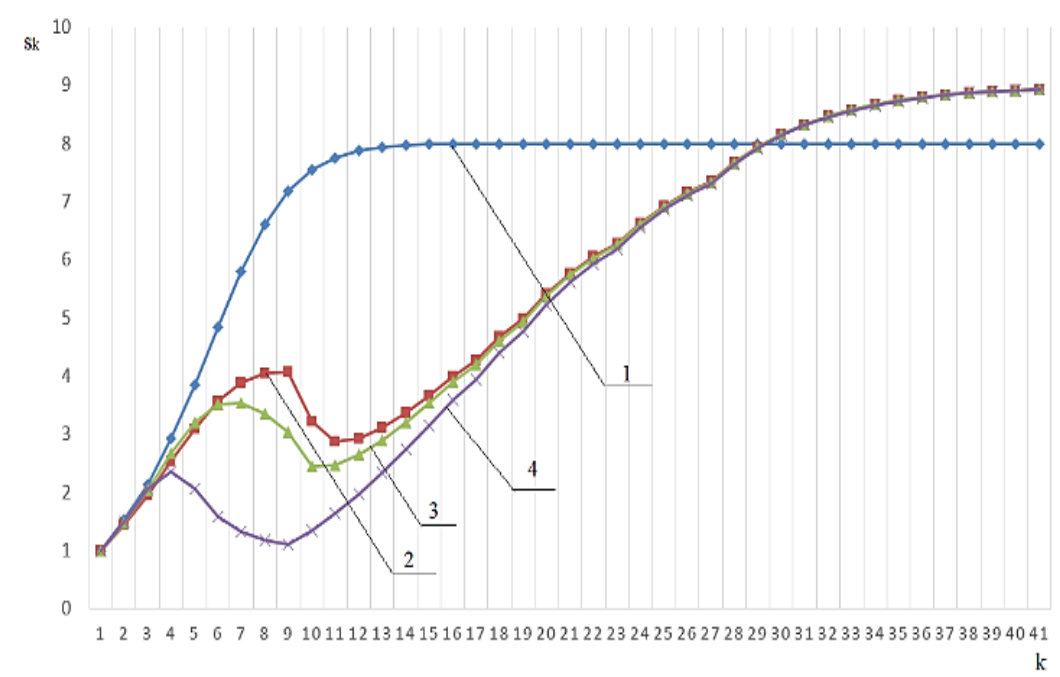

Figure 4. The change in VC2 resources as a result of counterattack: $1-S=8, d=0 ; 2-S=1, d=0,2 ; 3-S=1, d=0,1 ; 4-S=1, d=0$

\section{CONCLUSION}

For the first time, a conceptual information confrontation model of actors of virtual communities in SNS has been developed, which allows to take into account not only the quantitative change of actors in communities, but also the redistribution of the received resources of the information space and the cost of conducting the confrontation. The main point of the concept lies in the distribution and specialization of information about the actors' behavior in the context of antagonistic conflict in SNS across the layers to describe certain aspects of information confrontation. The first layer model describes the dynamics of the actors' number of two virtual communities in SNS that are in antagonistic conflict in the information space. The second layer model formalizes the growth of virtual community resources as a result of information confrontation in SNS. The third one determines the dynamics of resource expenditures for information confrontation in SNS. This approach separates models that describe conflict interaction from models that describe the winnings and losses of parties as a result of actors' information confrontation in SNS. The models describing the conflict interaction of virtual community actors can be used to model information operations in SNS and increase the effectiveness of counteracting threats to the state's information security. The separation of three layers in the model arranges the absence of need for the introduction of additional functionally dependent elements, and to reflect the relationship, the parametric connections are enough. This allows for further studies to consider the dynamics of information confrontation in virtual communities on the basis of a developed conceptual model with parametric control. 


\section{REFERENCES}

[1] R. Shailendra, et al. "Social network security: Issues, challenges, threats, and solutions," Information sciences, vol. 421, pp. 43-69, 2017. Available: 10.1016/j.ins.2017.08.063.

[2] S. Yevseiev, O. Korol and H. Kots, "Construction of hybrid security systems based on the crypto-code structures and flawed codes," Eastern-European Journal of Enterprise Technologies, vol. 4/9(88), pp. 4 - 20, 2017.

[3] L. Y. Huang, Y. J. Hsieh and Y. Wu, "Gratifications and social network service usage: The mediating role of online experience," Information \& Management, vol. 51(6), pp. 774-782, 2014. Available: 10.1016/j.im.2014.05.004.

[4] Y.Seo, Y. Kim, E. Lee and D. Baik, "Personalized recommender system based on friendship strength in social network services," Expert Systems with Applications, vol. 69, pp. 135-148, 2017. Available: 10.1016/j.eswa.2016.10.024.

[5] O. Trach and A. Peleshchyshyn, "Functional-network model of tasks performance of the virtual communities' life cycle directions," in Computer Sciences and Information Technologies (CSIT), pp. 108-110, 2016.

[6] Ye. Magda, "Hybrid War: Survive and Win," (in Ukrainian). Kyiv, Ukraine: Vivat Publishing, 2015.

[7] R. Hryshchuk and Yu. Danyk, "Cybersecurity fundamentals," (in Ukrainian). Zhytomyr, Ukraine: ZhNAU, 2016.

[8] V. Khoroshko and Yu. Khokhlachova, "Information warfare. Media as an instrument of information influence on society. Part 1,” (in Ukrainian), Bezpeka informatsii, vol. 22(3), pp. 283-288, 2016.

[9] A. Peleschyshyn, Z. Holub and I. Holub, "Methods of real-time detecting manipulation in online communities," in Computer Sciences and Information Technologies (CSIT), pp. 15, 2016.

[10] R. Hryshchuk and K. Molodetska-Hrynhchuk, "Methodological foundation of state's information security in social networking services in conditions of hybrid war," Information \& Security: An International Journal, vol. 41, pp. 55-73, 2018. Available: 10.11610/isij.4105.

[11] R. Hryshchuk, K. Molodetska and Yu. Serov, "Method of improving the information security of virtual communities in social networking services," in Proc. 1st International Workshop Control, Optimization and Analytical Processing of Social Networks, vol.2392, pp. 23-41, 2019. [Online], Available: http://ceurws.org/Vol-2392/paper3.pdf

[12] R. Hryshchuk and K. Molodetska, "Synergetic Control of Social Networking Services Actors' Interactions," in Recent Advances In Systems, Control And Information Technology, vol. 543, pp. 34-42, 2017.

[13] A. Peleshchyshyn, V. Vus, S. Albota, and O. Markovets, "A Formal Approach to Modeling the Characteristics of Users of Social Networks Regarding Information Security Issues," in Hu Z., Petoukhov S., He M. (eds) Advances in Artificial Systems for Medicine and Education II. AIMEE2018. Advances in Intelligent Systems and Computing, Springer, Cham, vol. 902, pp. 485-494, 2020.

[14] A. Peleshchyshyn, O. Markovets, V. Vus and S. Albota, "Identifying specific roles of users of social networks and their influence methods," in Proc. Computer Sciences and Information Technologies, CSIT 2018, pp. 39, 2018.

[15] G. Münkler, "Twenty-first Century Wars," (in Russian), International Journal of the Red Cross, pp. 7-24, 2003.

[16] J. Straub, "Mutual assured destruction in information, influence and cyber warfare: Comparing, contrasting and combining relevant scenarios," Technology in Society, pp. 101177, 2019.

[17] M. Kress, et al. "Lanchester model for three-way combat," European Journal of Operational Research, vol. 264(1), pp. 46-54, 2018. Available: 10.1016/j.ejor.2017.07.026.

[18] G. Feichtinger, A. Novak, S. Wrzaczek, "Optimizing counter-terroristic operations in an asymmetric Lanchester model," in IFAC Proceedings Volumes, vol. 45(25), pp. 27-32, 2012. Available: 10.3182/20120913-4-it-4027.00056.

[19] V. Yu. Chuev and I. V. Dubogray, "Models of bilateral military operations of numerous groups," Mathematical modeling and numerical methods, vol. 1(9), pp. 89-104, 2016.

[20] C. Barrett, S. Eubank and M. Marathe, "Modeling and simulation of large biological, information and socio-technical systems: an interaction based approach," in Interactive Computation, Springer, pp. 353-392, Heidelberg, 2006.

[21] M. Tabor, "Chaos and Integrability in Nonlinear Dynamics: An Introduction," Wiley, Michigan, 1989.

[22] H. Haken, "Advanced Synergetics: Instability Hierarchies of Self-Organizing Systems and Devices," SpringerVerlag, New York, 1993.

[23] M. Askarizadeh, B. T. Ladani and M. H. Manshaei, "An evolutionary game model for analysis of rumor propagation and control in social networks," Physica A: Statistical Mechanics and its Applications, vol. 523, pp. 21-39, 2019.

[24] A. Mandel and X. Venel, "Dynamic competition over social networks," European Journal of Operational Research, 2019. Available: https://doi.org/10.1016/j.ejor.2019.07.028.

[25] A. Hafezalkotob, M. Khodabakhsh, A. Saghaei and M. Eshghipour, "Cooperation of advertising companies in social networks: A graph and game theory approaches," Computers \& Industrial Engineering, vol. 125, pp. 212-220, 2018.

[26] L. Cui and C. Fang, "Reliability-Game Theory," in Advances in System Reliability Engineering, Academic Press, pp. 77-115, 2019.

[27] R. Isaacs, Differential games: a mathematical theory with applications to warfare and pursuit, control and optimization, Courier Corporation, 1999.

[28] M. T. Prior, "The interactional dynamics of scaling and contrast in accounts of interpersonal conflict," Journal of Pragmatics, vol. 150, pp. 92-110, 2018. Available: 10.1016/j.pragma.2018.11.020.

[29] I. Hrabar, Yu. Tymonin and Yu.Brodsky, "The universal model of the system: the methodological aspect," (in Ukrainian), Bulletin of ZhNAEU, vol. 1, pp. 202-209, 2009.

[30] K. Molodetska and Y. Tymonin, "System-dynamic models of destructive informational influence in social networking services," Intern. J. of 3D Printing Technologies and Digital Industry, vol. 3(2), pp. 137-146, 2019. 


\section{BIOGRAPHIES OF AUTHORS}
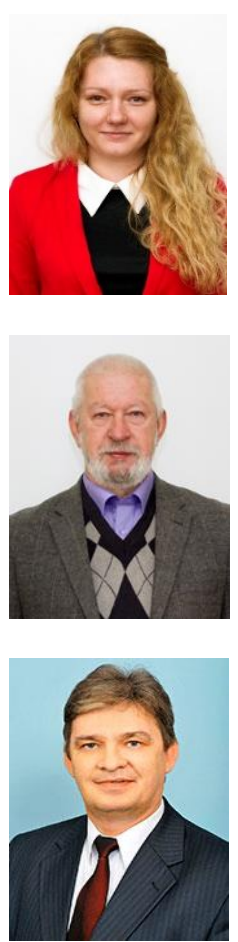

Kateryna Molodetska (1985), Doctor of Technical Sciences, Associate Professor, Professor of Computer Technology and Modeling Systems Department in Zhytomyr National Agroecological University. Graduated with honors from Zhytomyr Military Institute named after S. P. Korolyov. Studied at the postgraduate school of the Department of Hybrid Control and Modeling Systems in the Energy Institute of the Problems of Modeling in the Power Engineering named after G. E. Pukhov in the National Academy of Sciences of Ukraine. The sphere of scientific interests is connected with mathematical modeling and information security.

Yurii Tymonin (1945), Candidate of Technical Sciences, Associate Professor, Assistant Professor of Computer Technology and Modeling Systems Department in Zhytomyr National Agroecological University. Graduated from the Leningrad Electrotechnical Institute. Awarded the Silver Medal on the Exhibition of Achievements of the National Economy of the USSR and the Sign "Inventor of the USSR". The sphere of scientific interests is connected with simulation of processes and systems of various physical nature.

Ihor Melnychuk (1965), Doctor of Historical Sciences, Associate Professor, Head of Social Sciences Department in Zhytomyr National Agroecological University. Graduated from the Leningrad Military and Political School named after Andropov. Lectured at the Kiev Higher Engineering Radio Engineering College of Air Defense and Zhytomyr Pedagogical University. The sphere of scientific interests is connected with history of Ukrainian science, political science of the modern period and information security. 